\title{
From the North Pole to Tahiti-Initial Experiences with IODP and MSPs
}

\section{by Alister Skinner and Dan Evans}

When the British Geological Survey (BGS) compiled the consortium bid that later translated into the European Consortium for Ocean Research Drilling (ECORD) Science Operator (ESO) for the new Integrated Ocean Drilling Program (IODP), we stated that mission-specific platforms (MSPs) would introduce a fundamentally new dimension into scientific ocean drilling. Although this belief was based on our collective involvement in similar-type expeditions in various parts of the world, little did we realize just how much of a new dimension it was going to be for the operator as well as IODP management, scientific panels, proponents, and participants.

With the IODP Expedition 302, Arctic Coring Expedition (ACEX), now behind us, we question whether it set a pattern as the first of the MSP operations. In this article we compare ACEX to the current work we are engaged in, preparing for IODP Expedition 310, Tahiti Sea Level. It indicates how different and individual each MSP expedition will be-just as the name implies.

ACEX had a long gestation through various planning groups before the ESO inherited it, and without the head start that this provided, we would not have been able to conduct the expedition in 2005; It was a learning experience for the program fully to realize, however, that for MSP operations there is no firm plan before that plan is in place by way of signed and secured contracts with companies or contractors able to do the work. This is an issue with which we still grapple: how do we cope with commercial practices, legal tendering, and contractual issues while at the same time keep an eager science community fully informed about the status and likely logistics of the expedition? This is very different from the routine of the Ocean Drilling Program (ODP), where the vessel, on a continuous rolling contract, was always known, the timings for port calls were firmly fixed, and each project was allocated one leg of eight weeks. Also, it is fair to say that funding, which always will be an important issue to be taken into account, has a particular strong impact on field time available for a given MSP operation. Preparations for Tahiti are coming up against similar time constraints in decisions for contracting and disseminating specific information, including timing of operations to the wider scientific community, because tenders and contractual issues have yet, as of July 2005, to be completed. This places the program in a delicate balancing position regarding information dissemination, community discussion, and decision-making. It also places a strong requirement on the scientists to stick to the original specification as far as possible, because each change means compromise to fit all within predetermined budgets.

ACEX put into effect operations to meet the science requirements for a highly ranked drilling proposal in a high polar environment. Some aspects were special to that particular environment, but others will reoccur in every MSP operation. A key issue for the MSP operations is the fact that there is no single MSP vessel for the IODP. The ESO prepares an outline specification from operational information and prepares a call for interest from suitable contractors. This is followed by a detailed specification and tender process based on responses to the expressions of interest. Both of these operations have to be conducted in accordance with European Union regulations on fair competition and a legally binding timescale. Only after all of these legal requirements are put into effect is funding confirmed from the ECORD and the IODP. Then contracts are signed, the detailed equipment and operations planning come into play, and the scientists can be fully informed of the forthcoming project in terms of timing, drilling, and laboratory facilities. This means that within the scope of each project there is the procurement of a suitable platform or vessel, a technical plan for execution of the science, a mobilization of all equipment and personnel, and then the project execution. Upon completion, the whole apparatus is dismantled.

This concept was (we hope) at one extreme end of the spectrum for ACEX. No Arctic-class icebreaking drilling vessel suitable for the work was available, and additional support icebreakers also had to be contracted, together with specialist services, in order to undertake the work.

A North Sea anchor handling and supply boat with Baltic-class icebreaking capability (the Vidar Viking) was contracted in January 2004 for work commencing at the end of July 2004. A moonpool was designed as part of the contract and installed in May 2004 during a routine dry dock. At the same time, a drilling contractor, Seacore Ltd., of Cornwall, U.K., was chosen to design, build, and operate a suitable rig and associated machinery for installation on the vessel. The ESO worked with the U.S. implementing organization at Texas A\&M University to obtain drillpipe and build transportation containers in Houston, Texas, U.S.A. that ultimately became the drill floor for the 
operation. Both companies and the ESO worked closely together with advisors from the regulatory authorities. Captain Anders Backman was already identified as our Fleet Master, to ensure that the agreed workflow and timelines were met. While all this was occurring, the ship continued working on other projects until the last quarter of July 2004, when the mobilization commenced in Aberdeen, Scotland. Only at this stage did the day rates for the designated drilling vessel commence.

Also, in the closing weeks of January and into February, an agreement was signed with the Swedish Polar Research Secretariat for provision of the icebreaker Oden, ice management, helicopter, medical services, and the Russian nuclear icebreaker, Sovetskiy Soyuz. All vessels had different contracts and places for on and off hire. The Vidar Viking was chartered from Aberdeen to Aberdeen, the Oden from Gothenberg to Stockholm, and the Sovetskiy Soyuz from and to the ice edge, somewhere north of Norway, but with an agreed meeting date of all vessels at the ice edge on 10 August 2004.

During a period of six days in late July, the Vidar Viking was transformed from a bare boat into a drilling vessel by addition of the rig, mud system, drill floor, workshops, logging unit, petrophysics container, and core containers

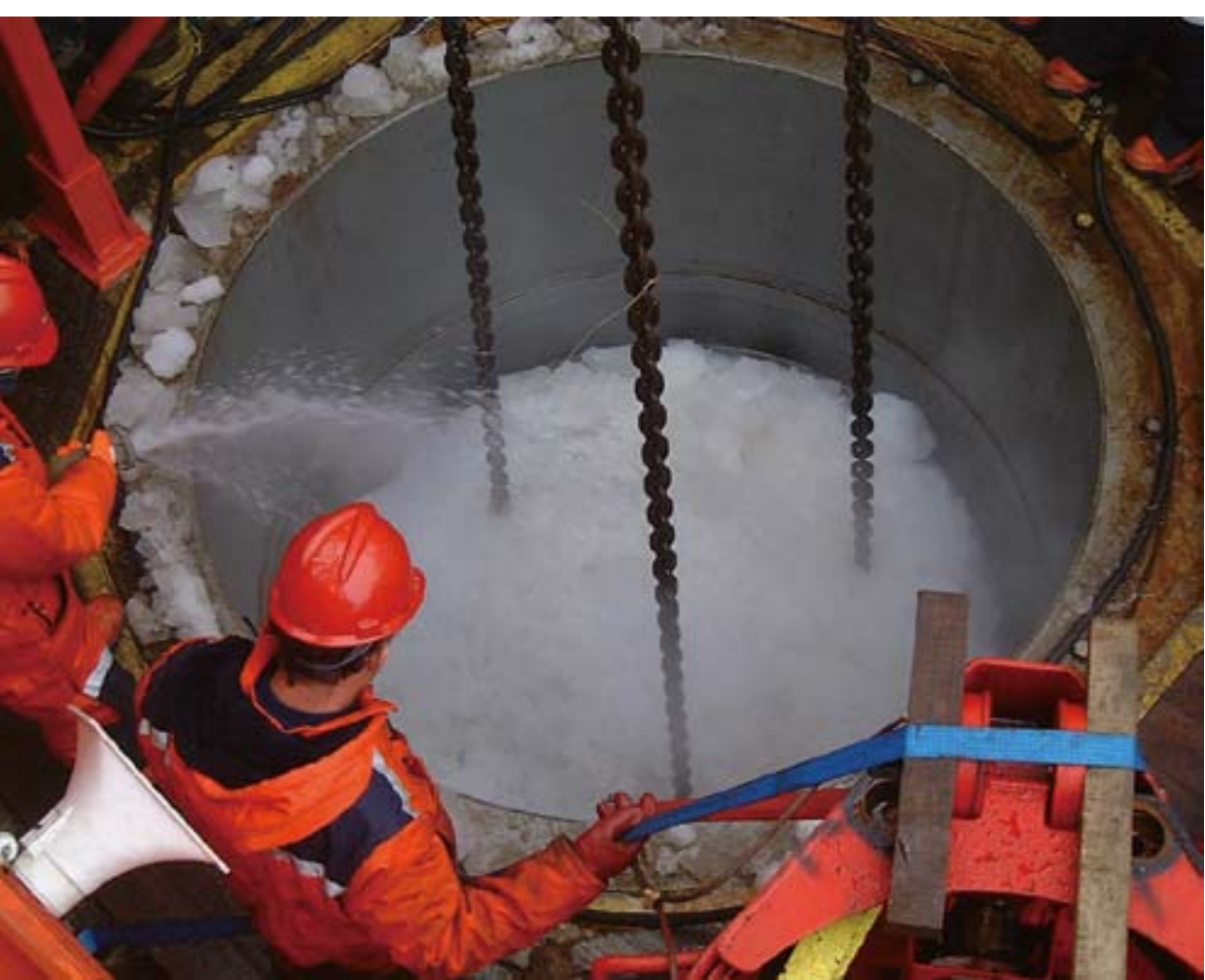

Figure 2. Clearing the moonpool to start work at the first site.

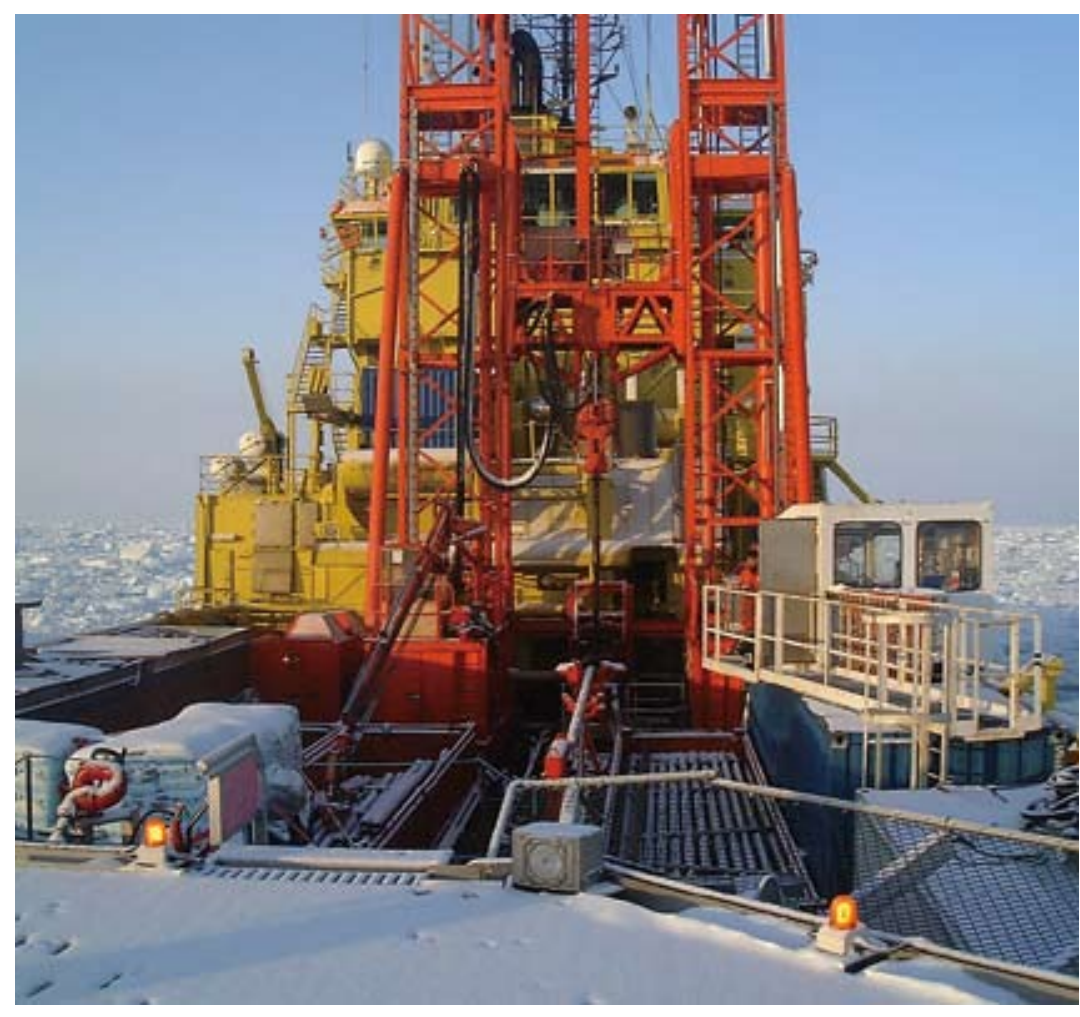

Figure 1. Drilling on a sunny day in the Arctic.

(Figs. 1 and 3). After sailing and testing the equipment in the North Sea to ascertain that all systems were functional, the vessel continued to Landskrona, Sweden, where the vessel's stern notch for working in ice, the helideck, and the curation laboratory from Bremen University (Germany) were installed. The stern notch and helideck are removed for North Sea operations and are routinely installed on the vessel as the ship returns to the Baltic Sea for winter icebreaking duties.

Before sailing from Landskrona, the Vidar Viking was fully transformed into an Arctic-capable drillship-all in a space of eleven days. The Vidar Viking met up with the Oden at a brief port call in Tromsø, Norway, and the science party embarked. The Russian escort joined the fleet a few days later, at the ice edge on 10 August 2004 as planned. This was the perfect culmination of a very busy schedule to meet the weather window available for the Arctic work.

On a normal drilling expedition, the next step would be to get on site and start drilling. Arctic conditions put a different slant on this. First, we had to be escorted to site, find a suitable ice-management plan for staying on location, remove all ice which had accumulated in the moonpool on transit (Fig. 2), fit the ice protection 
skirt into the moonpool and below the hull to protect the drillstring, and then try to position on site. Within hours it was established that dynamic positioning could not be utilized, because the conditions were much harsher than anticipated, and the drillship would also have to break ice. For the next three weeks, the captain and mates demonstrated their expertise in the art of seamanship and station keeping by traditional methods, albeit using some of the advantages of modern technology, while the Oden and the Sovetskiy Soyuz did a fantastic job around the Vidar Viking, mincing the ice floes into manageable, bite-size portions most of the time.

The Vidar Viking was too small to host the drilling operation and the science party (Fig. 3). The Oden became the nerve center for ice and scientific operations, with scheduled personnel transfers between vessels as required. Furthermore, only a subset of the full science party sailed on the expedition. Cores were not split on board. The main scientific component of the expedition took place at the University of Bremen after the expedition was completed and the cores sent ashore for examination by the full scientific party.

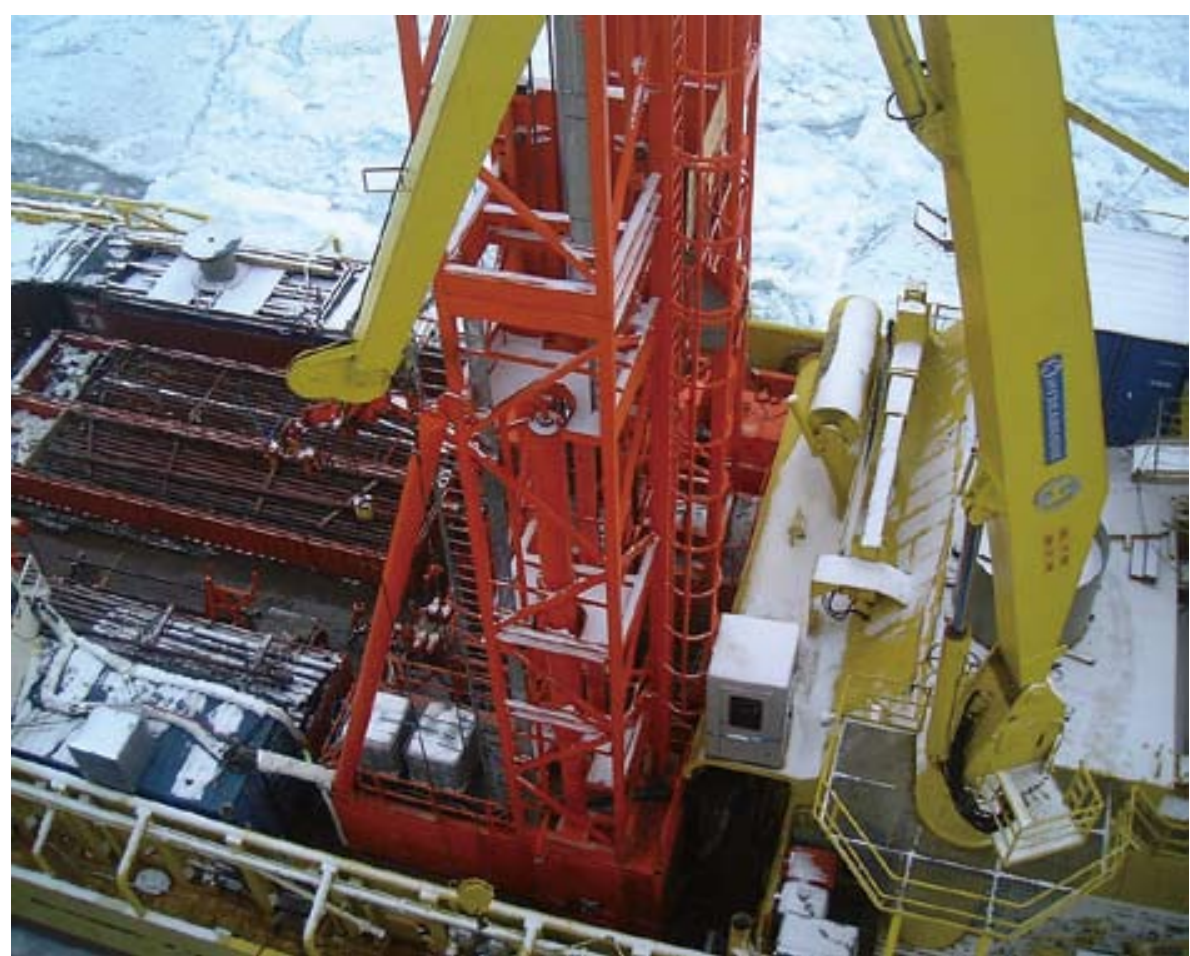

Figure 3. A cold evening - view onto the work deck of the Vidar Viking.

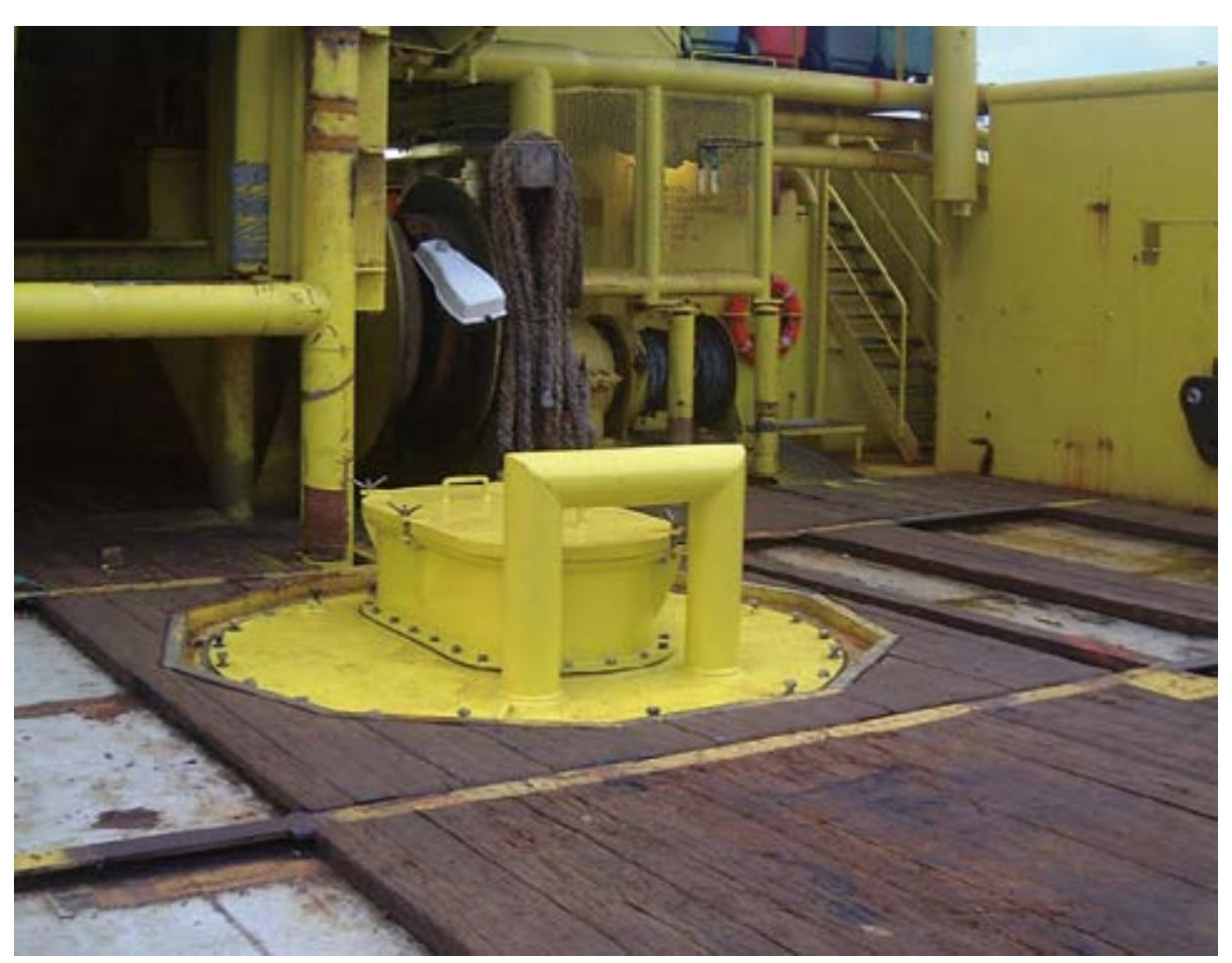

With close monitoring of the budget (for example, fuel costs alone varied from $\$ 6000$ to a maximum of $\$ 30,000$, depending on operations), the time for science was maximized within the available resources. On completion, the ships left the ice, and this signaled the commencement of demobilization. The Sovetskiy Soyuz came off charter at the ice edge and the Vidar Viking disembarked some personnel to the Oden, which headed for Tromsø to disembark all scientists and ESO-contracted personnel. The Oden then made onward transit to Stockholm for the end of her charter while the Vidar Viking made all speed to the southern coast of Norway, for a ship's crew change and demobilization of the drill rig. The Vidar Viking then continued to Landskrona with a reduced ESO and Seacore crew to remove the stern notch, helideck, cores, and curation laboratory, and to reinstall the chain locker instead of the moonpool (Fig. 4). The final stage of demobilization took place in Aberdeen, where the remainder of the Seacore, ESO, and Schlumberger equipment was removed.

After ACEX, it appeared that Expedition 310 to Tahiti would be a much more straightforward project

Figure 4. The moonpool returned to a chainlocker at the end of demobilization. 
in an easier area for logistics and operations, but, experiences so far suggest that there are equal but different challenges in store! Unlike the ACEX expedition to the Arctic, where the physical environment posed very strong limitations on the availability of suitable platforms, the soaringprice of oil in 2005 led otherwise interested vessel contractors to direct their fleet to the most booming markets. This made it extremely difficult to contract a suitable vessel for Tahiti at a price that would allow enough time on location to address the planned science. So despite tendering for drilling platforms and drilling contract as timely as possible, only as of very late July this year was it possible to complete a contract for a suitable drilling vessel for the Tahiti expedition planned to start in late

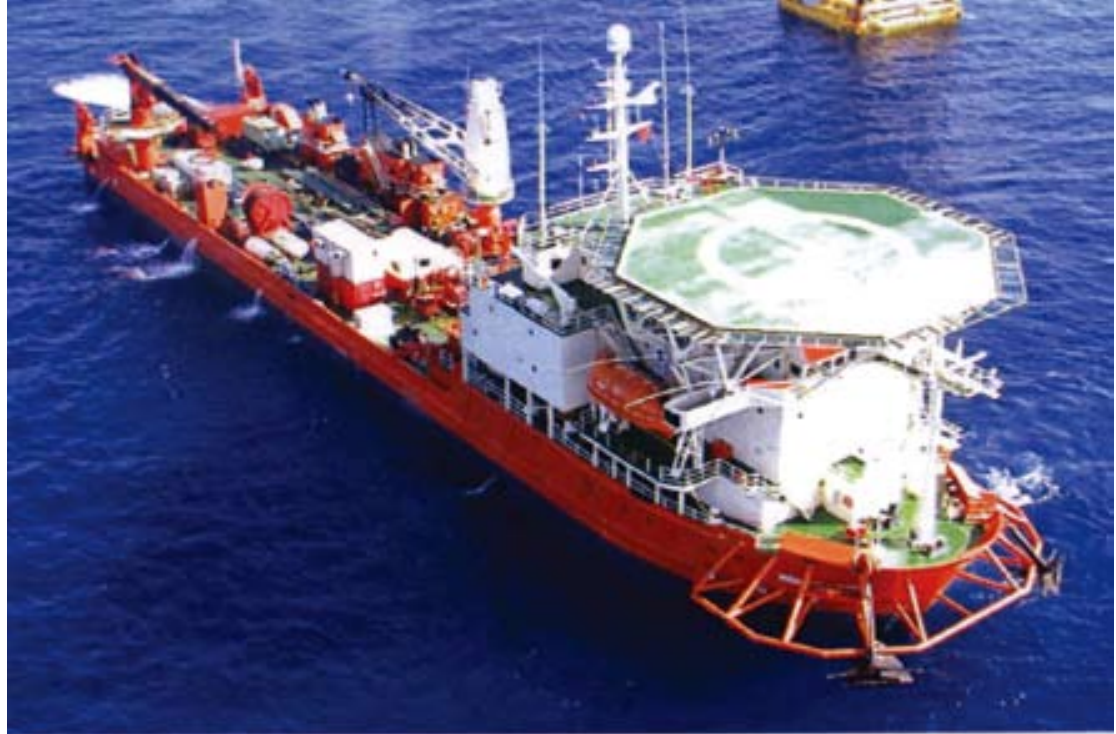

Figure 5. The dynamically positioned vessel Hunter will be used for drilling in Tahiti. September 2005. The vessel selected, with the help of the drilling contractor Seacore, is the dynamically positioned vessel Hunter (Fig. 5). The Hunter will offer ample space for the drilling equipment and good accommodation and working facilities for the seagoing part of the science party.

The expedition's close proximity to land, however, means that drilling permits and clearances are required, and coring in a coral reef environment requires an environmental impact assessment (Fig. 6). There are navigational issues surrounding the operation, such as potential interference with the international airport and navigation channel for the main port, Papeete, which are close to one area of work. A small, remotely operated vehicle (ROV) or camera system is likely to be required for pre- and post-drilling monitoring

of the sites. Until the vessel selected from tender was under contract, no further action could be taken on many of these issues. International legal requirements mean that the vessel owners are responsible for obtaining diplomatic clearances through the flag state of the selected vessel. Thus, ESO cannot prepare final equipment scenarios until the contractor and ship capability is fully known.

Rest assured, however, that ESO will always endeavor to overcome the challenges offered by MSP drilling and pursue the unique opportunities MSP operations provide IODP scientists for accessing difficult, yet important drilling locations, the challenge being water depth, sea ice, or fragile formations like carbonate reefs.

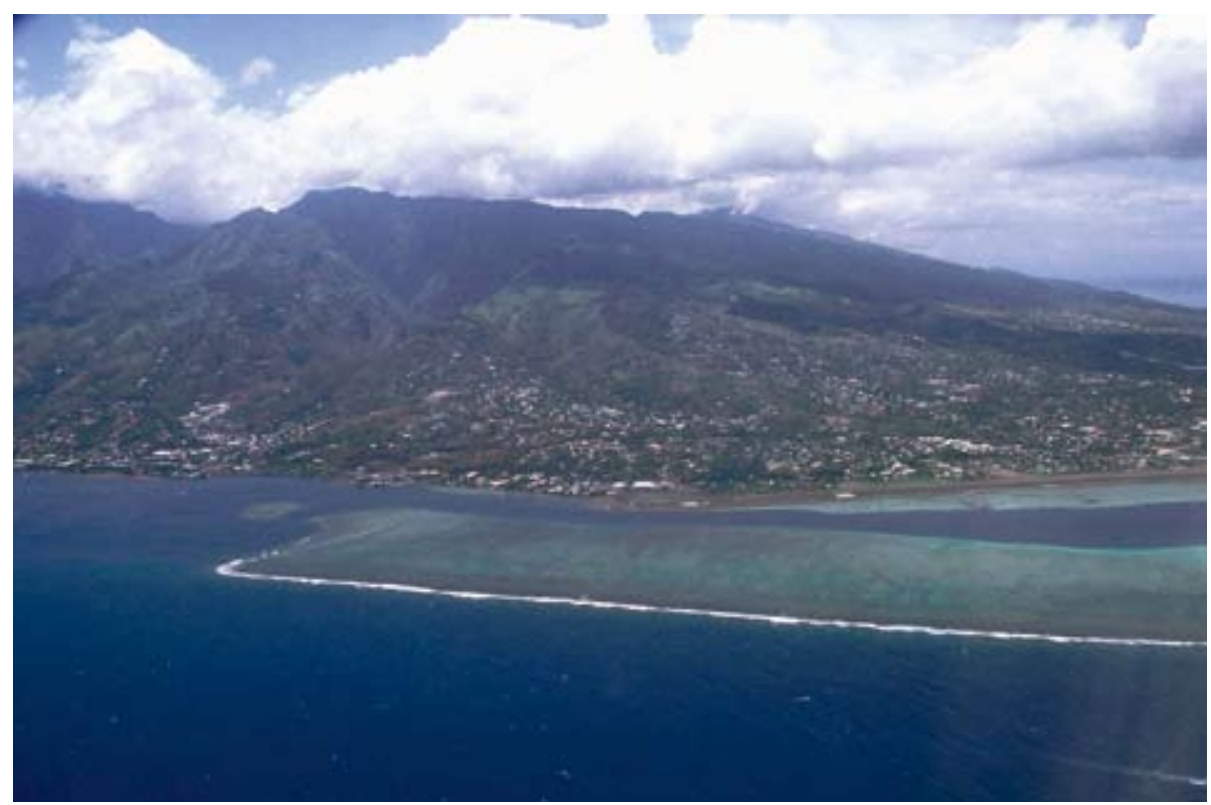

\section{Authors}

Alister Skinner and Dan Evans, ECORD Science Operator (ESO) and British Geological Survey, British Geological Survey, Marine Operations and Engineering, Murchison House, West Mains Road, Edinburgh EH9 3LA, Scotland, U.K., e-mail: acsk@bgs.ac.uk

\section{Related Weblink}

http://www.ecord.org/exp/tahiti/ 310.html

Figure 6. A potential drilling site of IODP Expedition 310 offshore Papeete (Tahiti). 